\title{
Epoxy hybrid composites reinforced with nanodiamond- silica for abrasive applications
}

\author{
Marcos Antônio Barcelos ${ }^{1,2 *}$ (D), Mariana Valinhos Barcelos ${ }^{2}$ (D), Gabriel Rodrigues de Almeida Neto ${ }^{3}$ (D), \\ Antônio Cesar Bozzi ${ }^{4}$ (D) and Rubén Jesus Sánchez Rodriguez ${ }^{1}$
${ }^{1}$ Laboratório de Materiais Avançados - LAMAV, Universidade Estadual do Norte Fluminense - UENF, Campos dos Goytacazes, RJ, Brasil
2Instituto Federal do Espírito Santo - IFES, Vitória, ES, Brasil Carlos - UFSCar, São Carlos, SP, Brasil \\ ${ }^{3}$ Programa de Pós-graduação em Engenharia e Ciência dos Materiais, Universidade Federal de São \\ ${ }^{4}$ Laboratório de Caracterização de Superfícies e Materiais, Departamento de Engenharia Mecânica, \\ Universidade Federal do Espirito Santo - UFES, Vitória, ES, Brasil \\ *mbbarcelos@yahoo.com.br
}

\begin{abstract}
In this work, a ternary composite of epoxy filled with ND and MS was produced for abrasive applications. Surfactants (oleic acid (OA), sodium dodecyl sulfate (SDS) and Triton TX-100 (TX-100)) were used to improve the particle dispersion and, consequently, the composite properties. The elastic modulus increased up to $76 \%$ for the sample with 1 $\mathrm{wt} \% \mathrm{ND}$ and $5 \mathrm{wt} \%$ ND using TX-100 (1ND5MS-TX100). Regardless of the filler concentration, the particles did not modify the thermal degradation behavior of the epoxy. Thermogravimetric (TGA) and dynamic mechanical (DMA) analyses suggest a strong particle-matrix interface, also evidenced in scanning electron microscope (SEM) micrographs. The composites presented superior tribological performance. 1ND5MS-TX100 presented a wear rate of $2.19 \times 10^{-3}$ $\mathrm{mm}^{3} . \mathrm{Nm}^{-1}, 61.3 \%$ lower than the epoxy. Also, all composites significantly reduced the roughness of the marble, being proportional to the abrasives concentration. Overall, composites with TX-100 presented improved wear behavior.
\end{abstract}

Keywords: epoxy, nanocomposites, nanodiamond, silica, surfactant, thermoset.

How to cite: Barcelos, M. A., Barcelos, M. V., Almeida Neto, G. R., Bozzi, A. C., \& Sánchez Rodriguez, R. J. (2021). Epoxy hybrid composites reinforced with nanodiamond-silica for abrasive applications. Polímeros: Ciência e Tecnologia, 31(3), e2021026. https://doi.org/10.1590/0104-1428.20210036

\section{Introduction}

The extraction and processing of ornamental stones is an important economic activity in many countries across the globe ${ }^{[1]}$. Currently, Brazil is the fourth-largest producer of ornamental stones in the world, with year production of 9.5 million tons. According to the Brazilian Association of the Ornamental Stones Industry (ABIROCHAS), only in 2019, Brazil exported 2.1 million tons of ornamental stones, representing a total of nearly US\$ 1 billion $^{[2]}$.

Polishing is one of the most critical steps for processing ornamental stones. This step aims to improve some characteristics of the stone, such as color, texture and beauty, in addition to provide unique properties for specific applications. Currently, a combination of resin and diamond, known as resin-based diamond abrasives, is the most common material used in the polishing process of marble and other ornamental stones.

Composites filled with particles with high hardness, such as diamond, silicon carbide, alumina, and other ceramic particles have been studied to improve the wear resistance of polishing tools ${ }^{[3]}$. In addition to the tribological properties, the particles are expected to enhance the stiffness and strength of the matrix ${ }^{[4]}$. The size of the particle plays an important role in the overall polishing performance. Larger particles tend to be more easily detached from the matrix, leading to premature failure. Another important factor is controlling the distribution and dispersion of the particles, which may impact the material stiffness, impact, and wear resistance ${ }^{[5]}$.

Nanodiamond (ND) and silica (MS) have been reported to improve the wear behavior of composites ${ }^{[6,7]}$. The addition of only $0.5 \mathrm{wt} \%$ of ND enhanced by $95 \%$ the wear rate of neat epoxy ${ }^{[6]}$. Friction coefficients of epoxy resin decreased by a factor of 4 with $7.5 \mathrm{vol} \%$ of $\mathrm{ND}^{[8]}$. It was also observed an increase of scratch resistance by the incorporation of $25 \mathrm{vol} \%$ of ND ${ }^{[9]}$. Similarly, MS was reported to improve the frictional coefficient and specific wear rate of epoxy composites $^{[7,10]}$ and to produce wear-resistant coatings ${ }^{[11,12]}$. The studies reported so far explored the individual addition of ND and MS in an epoxy resin. It has not been studied the combination of both fillers for the preparation of a hybrid composite of epoxy resin matrix. Also, the fillers were added to the epoxy matrix without surface treatment ${ }^{[9,10,12]}$ or with surface chemical modification ${ }^{[6-8,11]}$. To the best of the authors knowledge, no work has been reported on the addition of 
different surfactants to improve these particles dispersion in epoxy matrix, and consequently the tribological behavior.

In the present study, a ternary hybrid composite of epoxy resin reinforced by ND and MS was produced. The goal was to evaluate the effect of different surfactants and particles concentration on the mechanical, dynamical mechanical, morphological, and tribological properties of the composites. It is expected that the results of this work will contribute to the development of a novel composite material for the final step of polishing of ornamental stones.

\section{Materials and Methods}

\subsection{Materials}

The epoxy resin used in this study (DER 331 resin) is a transparent liquid of bisphenol-A diglycidyl ether (DGEBA) acquired from Dow Quimica S/A. The epoxy hardening agent was tetraethylene pentaamine (TEPA) obtained from Fluka. The ND $(0-250 \mathrm{~nm})$ was supplied by Diambra, and the MS $(0.5-10 \mu \mathrm{m}$, with approximately $80 \%$ of the particles between $1-5 \mu \mathrm{m}$ ) was obtained from Sigma-Aldrich. Acetone was the solvent used in this study, and it was supplied by Neon. The surfactants used were oleic acid (OA, Proquimios), sodium dodecyl sulfate (SDS, Labsynth) and Triton TM X-100 (TX-100, Sigma-Aldrich).

\subsection{Preparation of the composites}

Before the preparation of the composites, the ND and MS particles were dried at $100{ }^{\circ} \mathrm{C}$ for $2 \mathrm{~h}$. Then, the epoxy resin was dehydrated in a vacuum oven at 70 mbar and $90{ }^{\circ} \mathrm{C}$ to remove humidity and reduce the presence of bubbles. The particle size distributions were obtained in a Sympatec HELOS laser diffraction equipment with 3 bar of pressure, and their x-ray diffractogram was obtained by $\mathrm{x}$-ray diffraction analysis (XRD) in a Bruker D8 Advanced.

The ND and MS particles were used to prepare a ternary composite of epoxy / ND / MS with different surfactants. The surfactant concentration was pre-optimized to yield superior dispersion. First, the particles were dispersed with the surfactants $(1 \mathrm{~g}, 0.2 \mathrm{~g}$, and $5 \mathrm{~mL}$ for OA, SDS and TX100, respectively) in $20 \mathrm{~mL}$ of acetone by bath sonication (SolidSteel, $135 \mathrm{~W}$, frequency of $40 \mathrm{kHz}$ ) and mechanical stirring for $20 \mathrm{~min}$. Then, the suspension was added to the epoxy resin, mechanically stirred for $30 \mathrm{~min}$ at room temperature, and bath-sonicated under vacuum for $1 \mathrm{~h}$. TEPA was added to yield a DGEBA: TEPA ratio of 1 :
0.17 to achieve the stoichiometric ratio of epoxy / equivalent amine, according to the methodology presented in a previous study of our group ${ }^{[13]}$. It was mixed for at least $5 \mathrm{~min}$, and degassed under vacuum for $30 \mathrm{~s}$. The mixture was poured in a metallic mold and cured in a multistep process: $24 \mathrm{~h}$ at room temperature, $4 \mathrm{~h}$ at $60{ }^{\circ} \mathrm{C}, 4 \mathrm{~h}$ at $120^{\circ} \mathrm{C}$, and $2 \mathrm{~h}$ at $190{ }^{\circ} \mathrm{C}$. The mold dimension was $65 \times 12 \times 4 \mathrm{~mm}$ for flexural and impact testing and $7.94 \mathrm{~mm}$ diameter $\mathrm{x} 67.9 \mathrm{~mm}$ height for the samples for wear analyses. A silicon demolding agent was used to aid the removal of the specimens from the mold. The samples will be designated as xNDyMSSurfactant, where $\mathrm{x}$ and $\mathrm{y}$ are the weight fraction of ND and MS, respectively, and Surfactant is the surfactant used in this formulation when applicable (Table 1).

\subsection{Characterization of the composites}

The thermal stability, the interaction between the fillers and the polymer matrix, and the actual content of the fillers in the samples were evaluated by TGA in a TA Instruments TGA Q5000. It was used a sample size of $10 \mathrm{mg}$, in a temperature range of $35-950{ }^{\circ} \mathrm{C}$ at a heating rate of $10^{\circ} \mathrm{C} \cdot \mathrm{min}-1$, under an air flow rate of $25 \mathrm{ml} . \mathrm{min}^{-1}$.

The flexural properties of the samples were obtained in an Instron 5582s universal testing machine at $18^{\circ} \mathrm{C}$ with a humidity of $50 \%$. The analyses were performed according to ASTM D790, with a specimen size of $65 \times 12 \times 4 \mathrm{~mm}$, a crosshead speed of $1.4 \mathrm{~mm} . \mathrm{min}^{-1}$, and a span length of $50 \mathrm{~mm}$. Four specimens were used for each formulation. The elastic modulus (E), maximum strain $(\mathcal{E})$, and flexural strength $(\sigma \mathrm{m})$ were calculated and used for the discussion.

The impact properties of the composites were examined in a CEAST impact tester. Four specimens $(65 \times 12 \times 4 \mathrm{~mm})$ of each formulation with a $\mathrm{v}$-shaped notch were tested according to ASTM D256, using a $1 \mathrm{~J}$ pendulum and impact velocity of $3.46 \mathrm{~m} / \mathrm{s}$. The equipment was calibrated to determine the impact energy $\left(\mathrm{J} \cdot \mathrm{m}^{-1}\right)$ of each test. The samples average impact energy was determined.

The morphology of the fracture surface of the flexuraltested samples was analyzed in a Zeiss EVO MA 10 SEM. The samples were mounted on stubs and gold-sputtered. Energy dispersive $\mathrm{x}$-ray spectrometry (EDS) was used to map the distribution of $\mathrm{C}$ and $\mathrm{Si}$ on the samples fracture surface.

DMA analysis was performed in a TA Instruments Q800 dynamic mechanical analyzer to obtain the storage modulus (E'), loss modulus (E'), and tan $\delta$ (E”/E') of the samples. The samples were analyzed using a dual cantilever clamp, frequency of $1 \mathrm{~Hz}$, amplitude of $20 \mu \mathrm{m}$, a static

Table 1. The designation and the composition of the produced samples.

\begin{tabular}{|c|c|c|c|c|}
\hline Sample & Epoxy (wt\%) & ND (wt\%) & MS (wt\%) & Surfactant \\
\hline Matrix & 100 & 0 & 0 & - \\
\hline 1ND3MS & 96 & 1 & 3 & - \\
\hline 1ND3MS-OA & 96 & 1 & 3 & $\mathrm{OA}$ \\
\hline 1ND3MS-SDS & 96 & 1 & 3 & SDS \\
\hline 1ND3MS-TX100 & 96 & 1 & 3 & TX100 \\
\hline 1ND5MS & 94 & 1 & 5 & - \\
\hline 1ND5MS-OA & 94 & 1 & 5 & $\mathrm{OA}$ \\
\hline 1ND5MS-SDS & 94 & 1 & 5 & SDS \\
\hline 1ND5MS-TX100 & 94 & 1 & 5 & TX100 \\
\hline
\end{tabular}


force of $0.1 \mathrm{~N}$, a heating rate of $3{ }^{\circ} \mathrm{C} \cdot \mathrm{min}^{-1}$ from -90 to $190{ }^{\circ} \mathrm{C}$. The glass transition temperature $(\mathrm{Tg})$ is obtained by the peak of $\tan \delta$.

The wear behavior of the composites was analyzed in a Phoenix PLINT TE67 pin-on-disk tribometer coupled with the COMPEND 2000 control and data acquisition software (Figure 1). The analysis was performed for $10 \mathrm{~min}$, with a normal load of $70 \mathrm{~N}$, wear path radius of $27.42 \mathrm{~mm}$, a rotational speed of $150 \mathrm{rpm}$, a tangential speed of $0.42 \mathrm{~m} . \mathrm{s}^{-1}$, and a sliding distance of approximately $257 \mathrm{~m}$. Temperature and humidity were controlled by a Minipa MT-240 thermo hygrometer; the temperature ranged from $18.9{ }^{\circ} \mathrm{C}$ to $21.4{ }^{\circ} \mathrm{C}$, while the humidity ranged from $35 \%$ to $52 \%$. The composite cylinders were $56 \mathrm{~mm}$ height $\times 7.93 \mathrm{~mm}$ diameter. The ornamental stone selected for the test was white marble with green veins with a $76 \mathrm{~mm}$ diameter and $4 \mathrm{~mm}$ height, a central hole of $10 \mathrm{~mm}$ diameter, a lateral hole of $5 \mathrm{~mm}$ diameter and $4 \mathrm{~mm}$ height, which is only present on the side where the stone is fixed to the equipment. Extra care was taken during manipulation and cleaning to assure minimal contamination and, thus, interference in the test results ${ }^{[14]}$.

The marble surface's mean roughness $(\mathrm{Ra})$ before and after the wear tests was evaluated by laser confocal microscopy in a LEXT Olympus microscope. Roughness provides valuable information regarding the efficiency of the polishing process. Reducing the roughness is fundamental to minimizing contact deformation, heat generation, electrical current conduction, and other problems ${ }^{[15]}$.

All data obtained in this study were presented as mean \pm standard deviation unless stated otherwise. The samples were compared using one-way ANOVA followed by Fisher's post-hoc test in Minitab 17.3.1 to determine any statistically significant difference for a significance level of $95 \%$.

\section{Results and Discussions}

\subsection{Thermogravimetric analysis (TGA)}

The TGA curves provide the weight variation of the sample with the temperature (Figure 2). The fillers, ND and MS, presented high thermal stability. MS did not undergo any weight loss event at up to $800{ }^{\circ} \mathrm{C}$, while ND presented a single weight-loss event, starting at $545.6^{\circ} \mathrm{C}$, related to the oxidation process ${ }^{[16]}$. Regarding the polymer composite, there is not a notable difference in the thermal behavior between the samples with different surfactants. However, comparing to the matrix, the addition of the fillers slightly increased the thermal stability of the matrix. This may result from the interaction between the polymer chains and the fillers, requiring more energy to overcome it $^{[17,18]}$
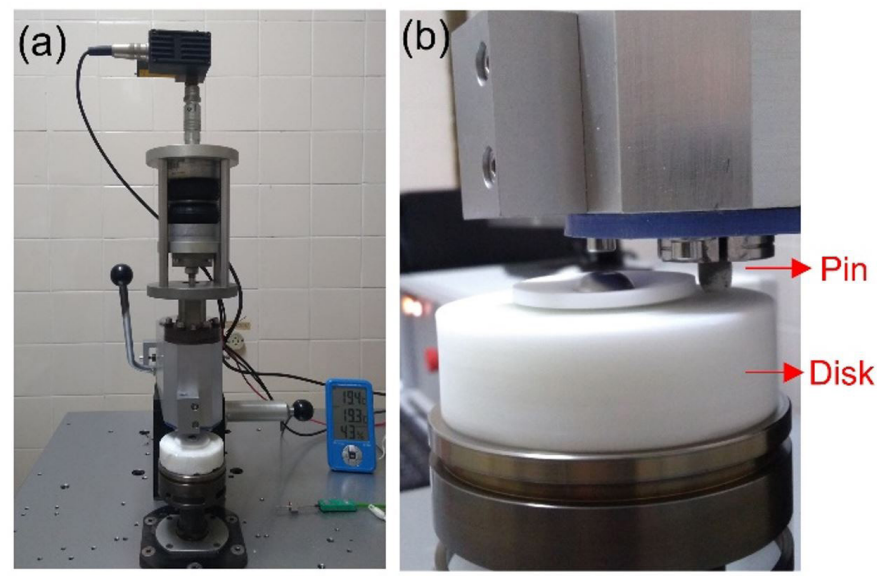

Figure 1. (a) Phoenix PLINT TE67 apparatus; (b) the contact between the composite pin and the disk.
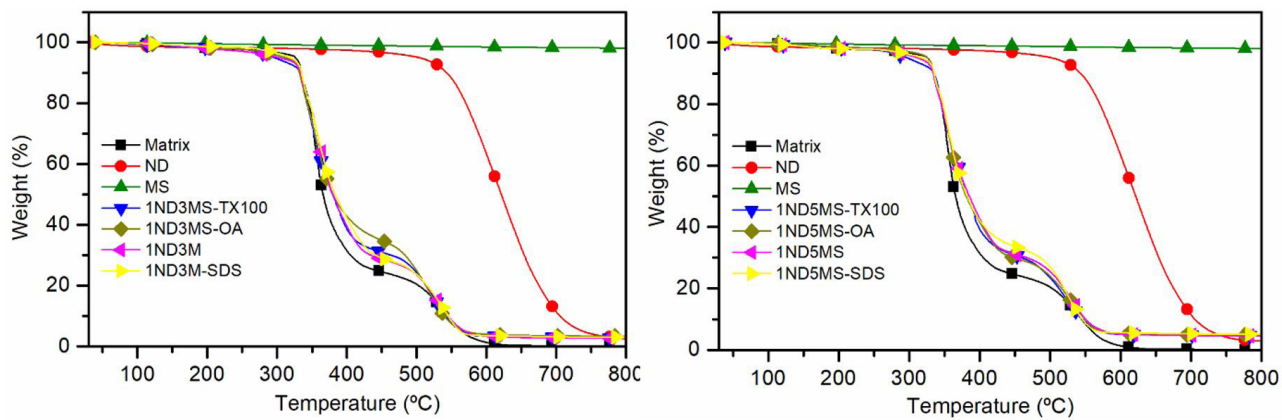

Figure 2. TGA curves of the particles, the epoxy matrix, and the produced composites. 
The weight fraction of MS present in the samples can be estimated by the residual weight at $800^{\circ} \mathrm{C}$, because at this temperature the matrix is fully decomposed, presenting a negligible residual weight, and the ND is fully oxidized. The mean residual weight of the composites was 2.83 and $4.51 \%$, agreeing with the weight fraction of MS added to each sample; the small difference is likely caused by the particle loss during the preparation process.

\subsection{Mechanical characterization}

The stress-strain curves obtained by flexural testing at room temperature are presented in Figure 3. The curve selected to represent the sample behavior was the one that presented the flexural properties closer to the mean values. Overall, the introduction of fillers reduced the flexural strength and maximum strain of the matrix; this reduction was proportional to the filler concentration. Depending on the polymer-filler interface properties and the dispersion degree of the fillers, high filler loading may reduce the macromolecular mobility, thus hindering deformation ${ }^{[19]}$.

The elastic modulus, on the other hand, presented a statistically significant increase $(p<0.05)$ by the introduction of the fillers regardless of the composition (Figure 4a). The matrix presented an elastic modulus of $1.54 \mathrm{GPa}$, which increased to up to $2.71 \mathrm{GPa}$ for 1ND5MS-TX100, representing a $76 \%$ increase. This percentage increase is higher than that observed for the
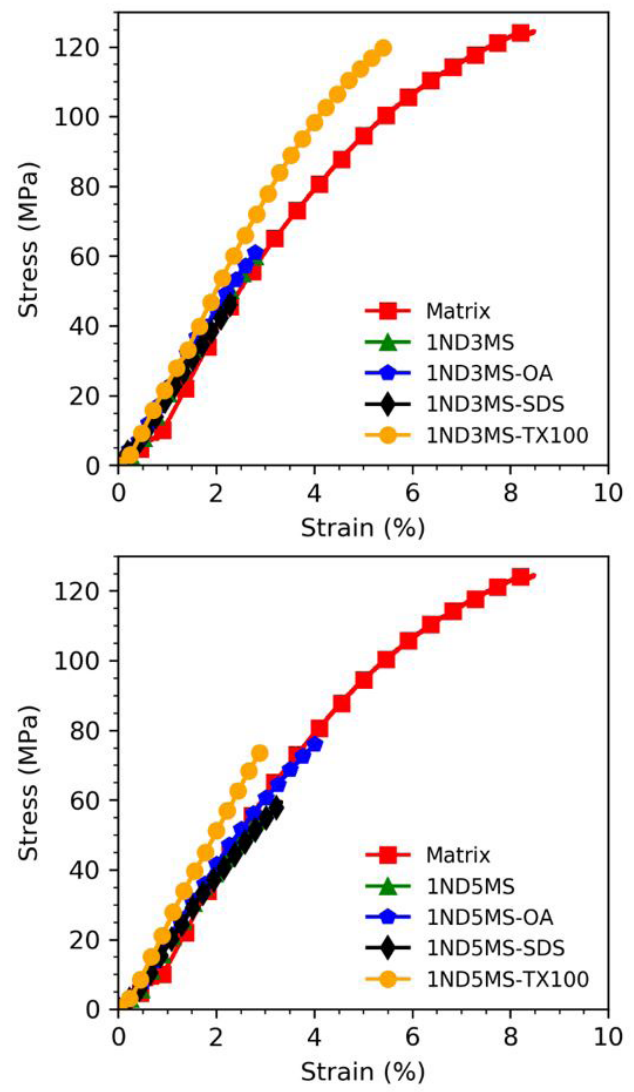

Figure 3. Stress $\times$ strain curves obtained by flexural testing for the samples produced. incorporation of up to $40 \%$ of micrometric diamond particles in the same type of epoxy matrix (DGEBA-TEPA) ${ }^{[20]}$. The mildest improvement of elastic modulus was for 1ND5MS-SDS, but it still increased by $22 \%$. The most significant improvement was found for $5 \mathrm{wt} \%$ fraction of MS, also suggesting a direct correlation with the filler concentration ${ }^{[21]}$. Diamond and silica are known for their high elastic modulus, but the overall performance of the composite does not depend exclusively on the filler elastic modulus; it also requires a strong interfacial interaction between the components. TX-100 was the most effective surfactant on increasing the elastic modulus. The other surfactants yielded similar results.

The impact resistance of an epoxy-based composite may reduce with a poor dispersion of the filler - acting as a stress concentrator - and with the presence of defects produced during the matrix curing step ${ }^{[22]}$. The mean energy absorbed by the samples during the fracture induced by the impact test is presented in Figure $4 \mathrm{~b}$. Apart from 1ND5MS-SDS, there was no significant difference in the energy absorbed by the samples compared to the matrix $(\mathrm{p}<0.05)$. The highest increase in the mean value was observed for 1ND5MS-OA (11.4\%). Even though the fillers did not improve the impact resistance of the epoxy matrix, they did not decrease it either. Therefore, it can be concluded that for high strain rates analysis, the effect of stress concentration was mild, and the ND and MS interfacial bonds were strong enough to maintain the energy absorption capacity of the system.
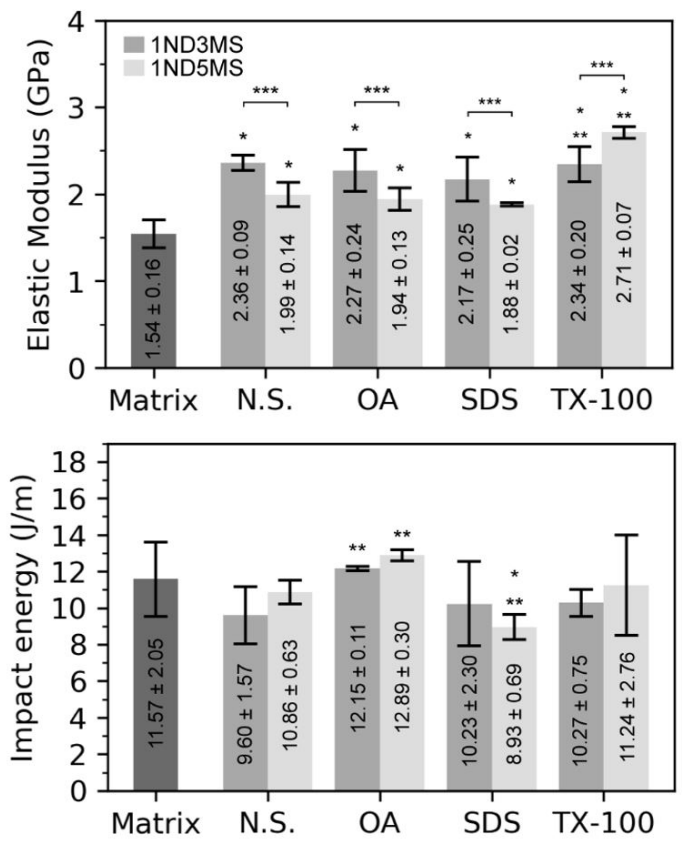

Figure 4. (a) Elastic modulus obtained in the flexural testing and (b) impact energy for the studied samples. N.S. stands for no surfactant. ${ }^{*} \mathrm{p}<0.05$ compared to the matrix, $* * \mathrm{p}<0.05$ compared to the N.S. system with the same concentration of particles, $* * * p<0.05$ compared to the system with the same surfactant but a different concentration of particles (One-way ANOVA, followed by Fisher's post-hoc test). 


\subsection{Morphological characterization}

The morphological aspects of the fracture surface of the samples after flexural testing were contrasting (Figure 5). Pure epoxy presented a smooth surface, with river patterns, a typical characteristic of brittle fracture ${ }^{[23,24]}$. On the other hand, the composites presented a rougher surface (Figure 5b), possibly due to crack deflection by the anchored particles $^{[22,25]}$. The fillers adhered to the surface after the fracture, possibly due to the strong bonding between the polymer matrix and the particles. From the micrographs, the quality of the processing conditions of the specimens was confirmed, as no voids from bubbles trapped into their interior were observed.

EDS element mapping is a useful tool to evaluate the particle dispersion qualitatively. The samples' fracture surface was mapped for identifying carbon and silicon (Figure 6). The region that contains silicon is represented in pink color, while green regions stand for the presence of carbon. Silicon, which is only present in the MS, is evenly distributed across the fracture surface of both samples (Figures $6 \mathrm{c}$ and $6 \mathrm{~d}$ ). The pink regions are more frequent and brighter for 1ND5MS, which is exclusively attributed to the higher loading of MS particles in this formulation. The dispersion of ND particles could not be evaluated by this analysis, because its main element (carbon) is the same as the epoxy matrix.

Despite the particles having nanostructured grains, confirmed by XRD analysis, they formed micrometric agglomerates (Figure 7). Nanodiamonds produced by the detonation route have a surface rich in oxygenated groups. The secondary forces between these groups, combined with the high surface
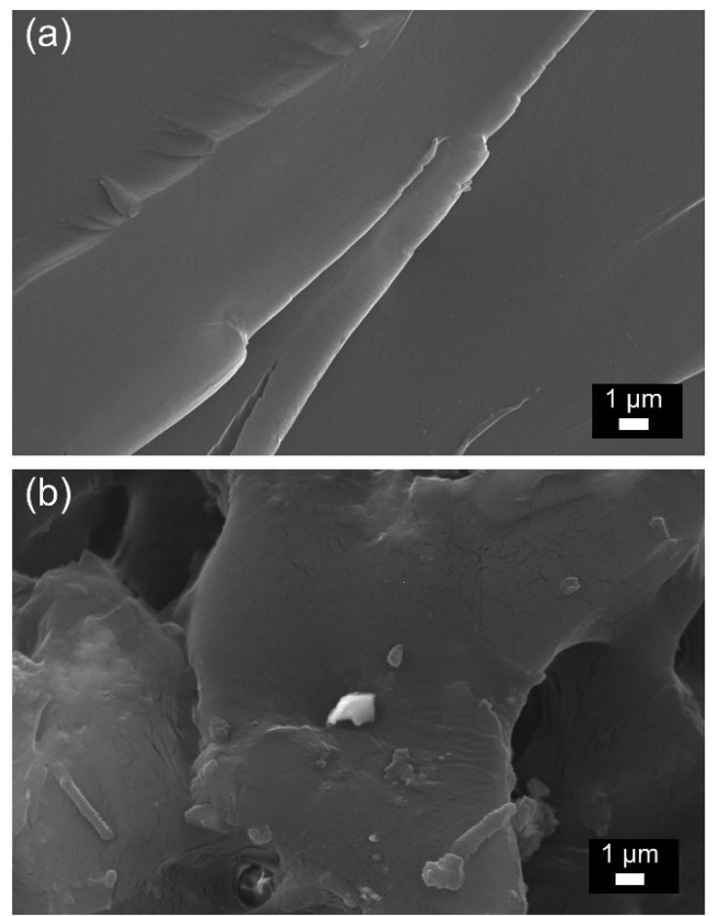

Figure 5. SEM micrographs of the fracture surface of (a) neat epoxy resin (b) and 1ND5MS. area per volume of the nanoparticles, are the driving force for the agglomeration. We have observed in another study the tendency of ND agglomeration ${ }^{[26]}$. The individual particles were analyzed by laser diffraction of dry dispersion before the addition to the matrix. A mean agglomerate size (x50,3) of $1.8 \mu \mathrm{m}$ and $1.5 \mu \mathrm{m}$ was obtained for ND and MS, respectively.

Agglomerates as large as $24.9 \mu \mathrm{m}$ and $17.9 \mu \mathrm{m}$ were found on the fracture surface of 1ND3MS and 1ND5MS. The use of surfactants effectively reduced the agglomerate size. OA was the least effective surfactant, but still significantly hindered the formation of agglomerates, reaching $4.3 \mu \mathrm{m}$ and $9.1 \mu \mathrm{m}$, for 1ND3MS-OA and 1ND5MS-OA, respectively. The agglomeration of the particles decreased even more with SDS and TX-100. The effect of these surfactants was similar for higher loadings: $2.1 \mu \mathrm{m}$ and $2.3 \mu \mathrm{m}$ for 1ND5MS-SDS and 1ND5MS-TX100, respectively. For lower loadings, TX100 was slightly more effective, producing agglomerates of up to $2.9 \mu \mathrm{m}$, as opposed to $3.1 \mu \mathrm{m}$ of SDS.

\subsection{Dynamical mechanical characterization}

The DMA curves presented in Figure 8 show the influence of the fillers on the viscoelastic properties of epoxy resin. The summary of the properties obtained is presented in Table 2. The damping behavior obtained by this analysis is sensitive to the material's interface; therefore, to elucidate the contribution of each filler interface, samples containing only ND and surfactants were also tested ${ }^{[27]}$ (Figure 8a).

The values of the storage modulus of the samples were similar. All samples displayed the same behavior with increasing temperature. Initially, the storage modulus smoothly decreased, and then, it dropped two orders of magnitude. The sharp reduction is associated with the onset of collaborative motion of the chain segments, which can facilitate mechanical failure.

The addition of ND shifted Tg to higher temperature, increasing from $127.2^{\circ} \mathrm{C}$ to $137.5^{\circ} \mathrm{C}$. The surfactants were effective in increasing it even more, reaching $145.5^{\circ} \mathrm{C}$ for $\mathrm{OA}$ and SDS. Usually, such behavior is a consequence of the restricted motion of the polymer chains because of the interaction with the filler. Therefore, the improvement after the addition of surfactants might result from the improved interfacial interaction between the matrix and the particles and the enhanced particle dispersion ${ }^{[27,28]}$.

Kubát et al. ${ }^{[27]}$ proposed a parameter A (Equation 1), which estimates the contribution of the interface to the overall damping of the composite; in other words, it can estimate the interaction strength between the filler and the matrix $^{[28]}$. If A equals zero, there is no dissipation of energy on the interface and good adhesion. Higher values of A suggest a larger contribution of damping for the interface. The A values calculated for the system with $1 \mathrm{wt} \% \mathrm{ND}$ (Table 2) show the positive effect of the surfactants on the interaction between the filler and the matrix. The composites with surfactant presented significantly smaller A than that of the composite without surfactant.

$$
A=\frac{1}{1-v_{f}} \frac{\tan \delta_{c}}{\tan \delta_{m}}-1
$$

$$
\tan \delta_{c}=\left(1-\mathrm{B} v_{f}\right) \tan \delta_{m}
$$



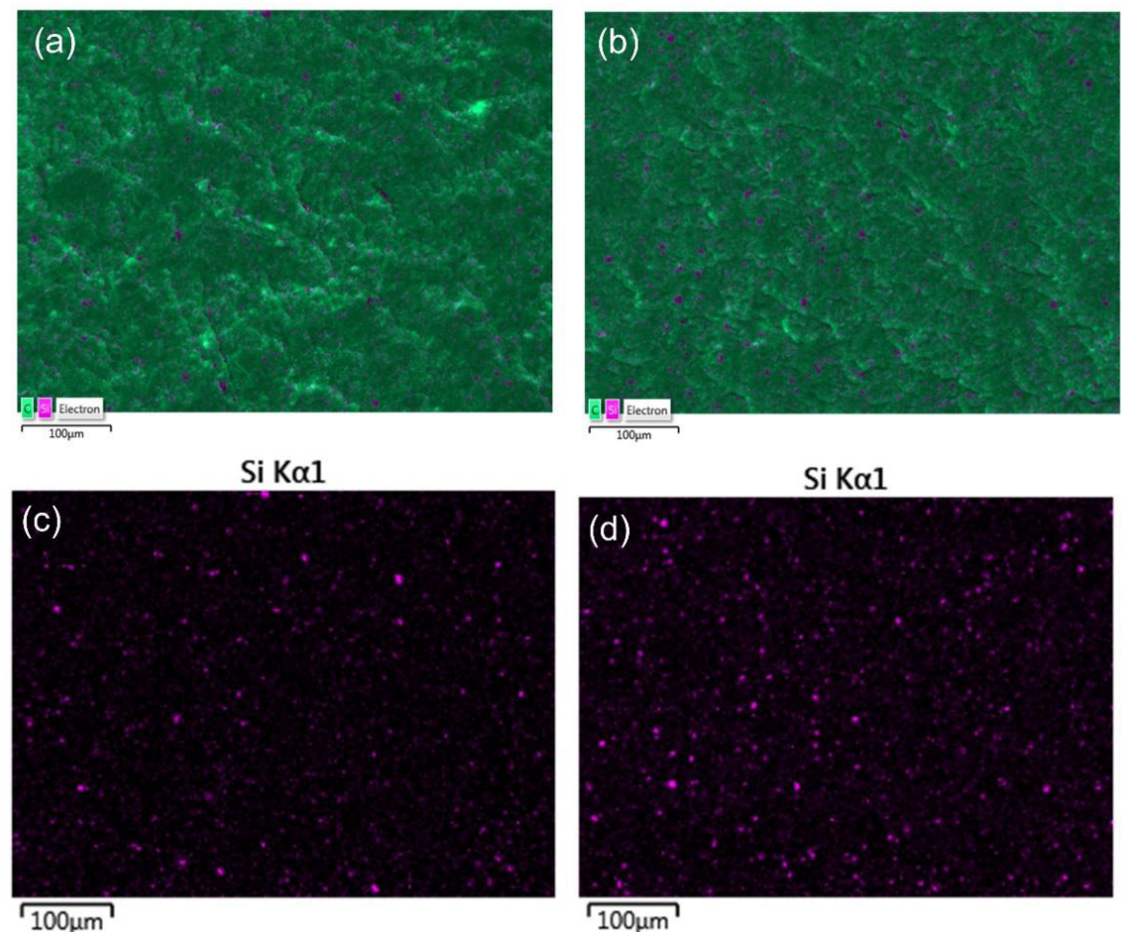

Figure 6. EDS element mapping of $\mathrm{C}$ (green) and Si (pink) on the fracture surface of 1ND3MS (a and c) 1ND5MS (b and d).

Table 2. Summary of the samples properties obtained by DMA.

\begin{tabular}{|c|c|c|c|c|}
\hline Sample & $\operatorname{Tg}\left({ }^{\circ} \mathrm{C}\right)$ & $\operatorname{Tan} \delta$ at $T_{g}$ & $\mathbf{A}$ & B \\
\hline Matrix & 127.2 & 0.6685 & - & - \\
\hline 1ND & 137.5 & 0.6784 & 0.02 & -4.00 \\
\hline 1ND-AO & 145.5 & 0.4957 & -0.26 & 69.86 \\
\hline 1ND-SDS & 145.5 & 0.4935 & -0.26 & 70.75 \\
\hline 1ND-TX100 & 138.1 & 0.5235 & -0.21 & 58.62 \\
\hline 1ND3MS & 122.2 & 0.5609 & - & - \\
\hline 1ND3MS-AO & 130.1 & 0.5635 & - & - \\
\hline 1ND3MS-SDS & 138.6 & 0.6063 & - & - \\
\hline 1ND3MS-TX100 & 116.6 & 0.5409 & - & - \\
\hline 1ND5MS & 147.3 & 0.5106 & - & - \\
\hline 1ND5MS-AO & 137.5 & 0.5566 & - & - \\
\hline 1ND5MS-SDS & 145.3 & 0.4906 & - & - \\
\hline 1ND5MS-TX100 & 112.2 & 0.5114 & - & - \\
\hline
\end{tabular}

where $v$ is the volume fraction, and the subscripts $\mathrm{f}, \mathrm{c}$ and $\mathrm{m}$ refer to filler, composite and matrix, respectively.

Ziegel and Romanov ${ }^{[29]}$ proposed a volume term B to account for the formation of immobilized interphase because of strong adhesion between particle and matrix (Equation 2). Again, the composites treated with surfactants presented higher B than the neat composite (Table 2). This suggests the formation of a thicker interphase layer ${ }^{[28]}$ for the composites with surfactant.

Regarding the hybrid composites, overall, Tg increased from a $3 \mathrm{wt} \%$ to $5 \mathrm{wt} \%$ MS concentration. This may be related to the restriction of the macromolecular motion of the epoxy matrix by the incorporation of the particles.
For the 1ND3MS samples, a clear response regarding the type of surfactants used was not observed. However, for the 1ND5MS composition, the Tg of all samples prepared with surfactants were smaller than that of 1ND5MS sample. Amongst the surfactants, TX-100 presented the largest decrease in the $\mathrm{Tg}$. This effect can be related to a different distribution of free volume between the systems. The addition of fillers with a high ratio of surface area per volume creates a large volume of polymer-filler interface ${ }^{[30]}$. The same particles with improved dispersion degree have larger interfacial free volume. This additional free volume facilitates the chain mobility in this region ${ }^{[31]}$. Thus, a possible explanation for the reduction of Tg for the samples using TX-100 is the reduction of the agglomerate 

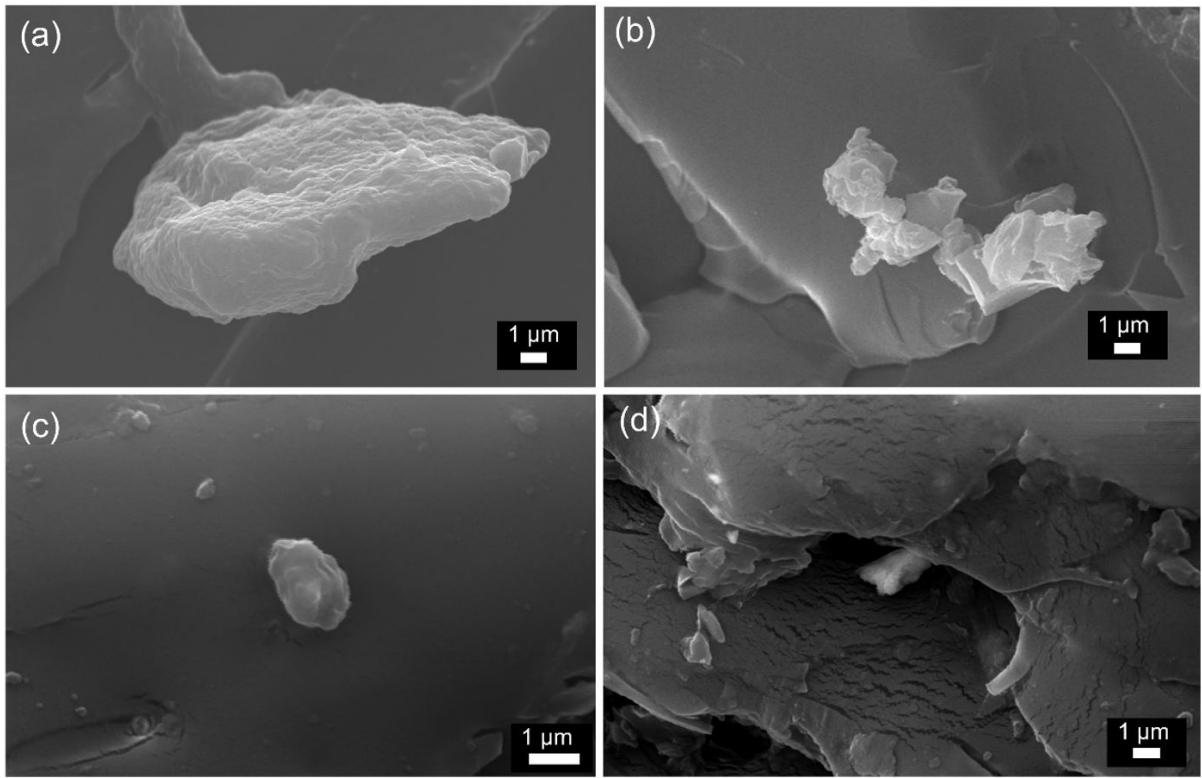

Figure 7. SEM micrographs showing agglomerates on the fracture surface of (a) 1ND5MS; (b) 1ND5MS-OA; (c) 1ND5MS-SDS; (d) 1ND5MS-TX100.
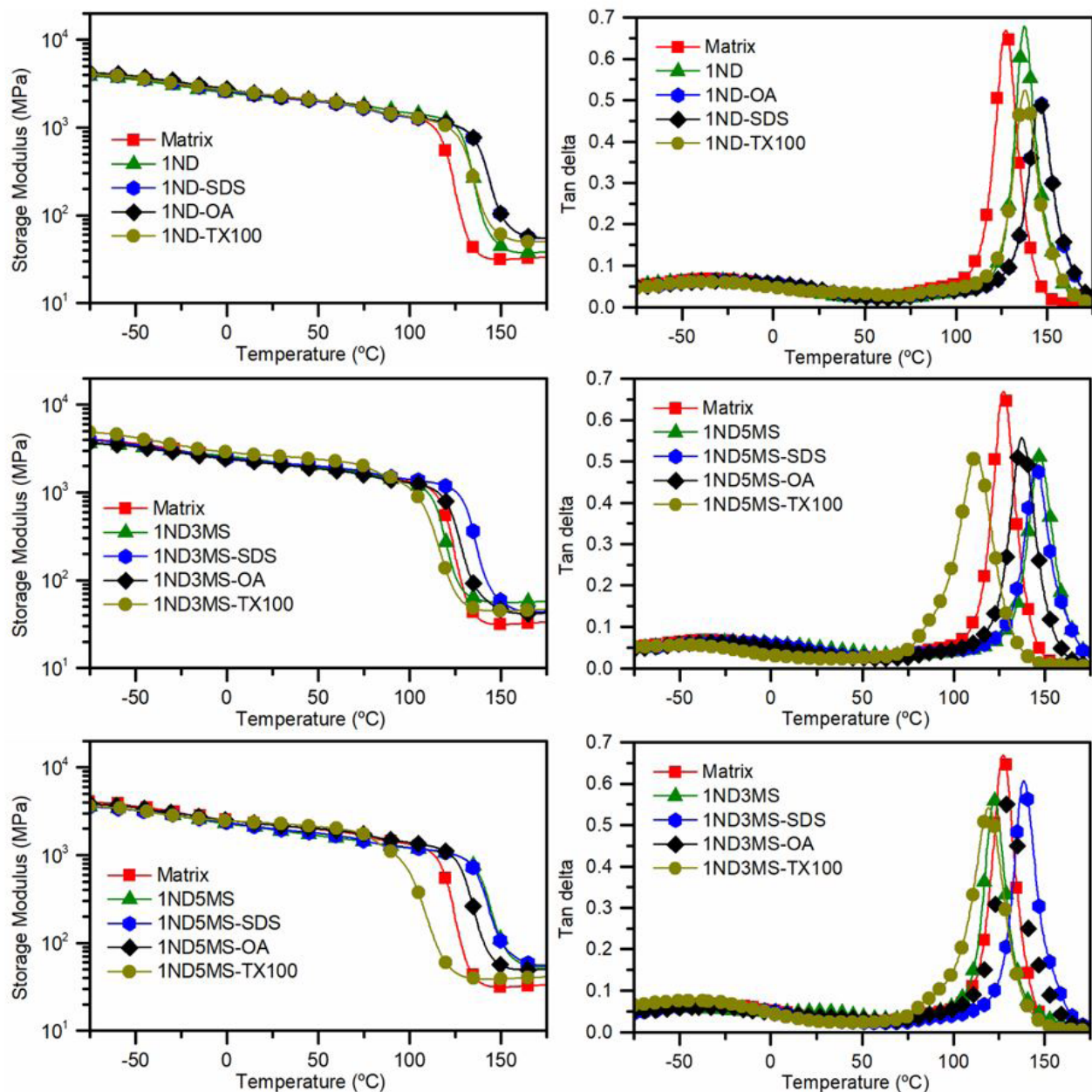

Figure 8. Evolution of storage modulus and tan delta with the temperature for all studied samples. 
(a)

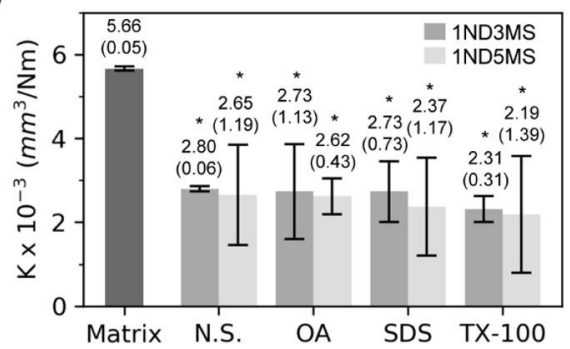

(b)

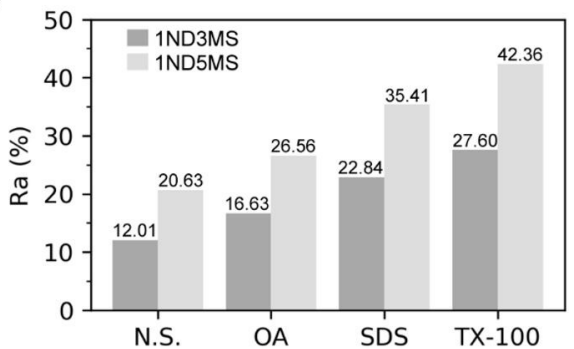

(c)

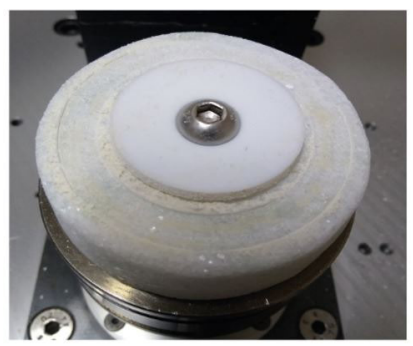

(d)

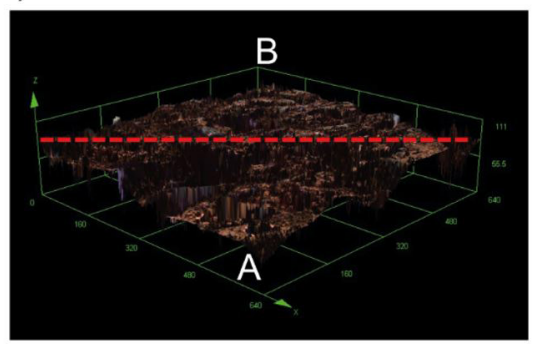

Figure 9. Influence of the surfactant used and abrasive particles concentration on (a) the wear rate (k) and (b) the reduction of the mean roughness $(\mathrm{Ra})$ of the marble after polishing with the samples. N.S. stands for no surfactant; (c) Photo of the polished marble after the wear test, and 3D image of the transition between the $(\mathrm{d}-\mathrm{A})$ unpolished and $(\mathrm{d}-\mathrm{B})$ polished region of the marble. In (a), the data is presented as mean (standard deviation). ${ }^{*} \mathrm{p}<0.05$ compared to the matrix (one-way ANOVA, followed by Fisher's post-hoc test).

size, which was previously discussed in the morphological characterization, and reflected in the sample's flexural elastic modulus and tribological properties (to be discussed). However, a possible plasticizing effect of the surfactants cannot be discarded ${ }^{[30]}$

Kubát et al. ${ }^{[27]}$ and Ziegel and Romanov ${ }^{[29]}$ parameters could not be used to assess the interface of the hybrid composites, as they were designed for single fillers, and it cannot account for the individual contributions and interactions of each filler. However, there was no significant difference between the height of tan delta peaks of the composites, suggesting that there was no effect of the surfactants between these formulations.

\subsection{Tribological analysis}

The influence of the hard and stiff ND and MS particles on the wear behavior of the epoxy matrix was evaluated in terms of the wear rate (k) and the average surface roughness (Ra) (Figure 9). The k values were considerably reduced for the composites (Figure 9a) $(\mathrm{p}<0.05)$. 1ND5MSTX100 presented a $\mathrm{k}$ of $2.19 \times 10-3 \mathrm{~mm}^{3} . \mathrm{Nm}^{-1}, 61.3 \%$ lower than that of the neat epoxy matrix. Ayatollahi et al. [6] observed a reduction of $95 \%$ of $\mathrm{k}$ for $0.5 \mathrm{wt} \%$ of aminofunctionalized ND with a diameter of 9-15 nm, indicating the important role of well-dispersed nanoparticles. Similarly, Zhang et al. ${ }^{[7]}$ reported a greater reduction of $\mathrm{k}$ for surfacefunctionalized nanosilica. Oppositely, in another study ${ }^{[11]}$, $5.9 \mathrm{wt} \%$ of nanosilica increased $\mathrm{k}$ of epoxy resin, the authors suggest the role of nanoparticle agglomeration on the wear behavior. A strong interface between the matrix and particles might be the reason for the improved wear resistance in our study ${ }^{[8]}$. Overall, $\mathrm{k}$ of the composites was similar, and no difference was observed among the surfactants used.
The reduction of the marble roughness after polishing with the samples did not follow the same trend as that of $\mathrm{k}$ (Figure 9b). The difference of Ra was higher for the samples with a surfactant, being the least effective to the most effective: OA, SDS, and TX-100. Also, it was observed that the Ra increased with the concentration of MS for the system with and without surfactant, showing proportionality to the abrasive particle concentration. 1ND5MS-TX100 presented the highest Ra, $42.4 \%$, nearly $105 \%$ higher than that of 1ND5MS. The wear track was seen by visual observation (Figure 9c). Laser confocal microscopy (Figure 9d) confirms the efficiency of the composites produced herein for the polishing of ornamental stones, showing a higher difference of the height of peaks and valleys in the unpolished region. The wear behavior of the composites results from the physical properties of the fillers, such as hardness, which has a primary role in the polishing procedure. The improved elastic modulus obtained in this study is also beneficial for the desired application ${ }^{[7,10,12]}$.

\section{Conclusions}

Hybrid composites of epoxy filled with nanodiamond and silica were successfully produced. The surfactants effectively reduced the tight agglomerates formed by the nanoparticles; however, micrometric clusters were still observed. The impact energy of the composites was not smaller than that of the neat matrix, which is expected when there are agglomerates that may act as a stress concentrators. The synergetic combination of the particles improved the flexural elastic modulus and the wear behavior of the composites. The sample 1ND5MS-TX100 was the one that presented the best results. In addition to presenting the smallest agglomerates, the elastic modulus increased by $76 \%$, 
the mean impact energy raised $11.4 \%$; it also displayed the lowest wear rate and the most significant reduction in the roughness of the polished marble. Therefore, this epoxybased composited containing nanodiamond and silica with the addition of TX-100 is promising for abrasive applications, such as the polishing of marble stones.

\section{Acknowledgements}

This study was financed in part by the Coordenação de Aperfeiçoamento de Pessoal de Nível Superior - Brasil (CAPES) - Finance Code 001. The authors would like to thank to Conselho Nacional de Desenvolvimento Científico e Tecnológico (CNPq) (process 310108/2017-9), FAPERJ (process E-26/203.016/2018) and Ifes for the financial support.

\section{References}

1. Elkarmoty, M., Bonduà, S., \& Bruno, R. (2020). A 3D optimization algorithm for sustainable cutting of slabs from ornamental stone blocks. Resources Policy, 65, 101533. http:// dx.doi.org/10.1016/j.resourpol.2019.101533.

2. Associação Brasileira da Indústria de Rochas Ornamentais ABIROCHAS. (2019). Balanço das exportações e importações brasileiras de rochas ornamentais em 2019. Brasília: ABIROCHAS. Retrieved in 2021, October 12, from https://abirochas.com.br/ wp-content/uploads/2020/06/Informe-01_2020-Balanço-2019. pdf

3. Lee, G. Y., Dharan, C. K., \& Ritchie, R. O. (2002). A physically-based abrasive wear model for composite materials. Wear, 252(3-4), 322-331. http://dx.doi.org/10.1016/S00431648(01)00896-1.

4. Hutchings, I., \& Shipway, P. (2017). Tribology friction and wear of engineering materials. United Kingdom: ButterworthHeinemann.

5. Móczó, J., \& Pukánszky, B. (2008). Polymer micro and nanocomposites: Structure, interactions, properties. Journal of Industrial and Engineering Chemistry, 14(5), 535-563. http:// dx.doi.org/10.1016/j.jiec.2008.06.011.

6. Ayatollahi, M. R., Alishahi, E., Doagou-R, S., \& Shadlou, S. (2012). Tribological and mechanical properties of low content nanodiamond/epoxy nanocomposites. Composites. Part B, Engineering, 43(8), 3425-3430. http://dx.doi.org/10.1016/j. compositesb.2012.01.022.

7. Zhang, M. Q., Rong, M. Z., Yu, S. L., Wetzel, B., \& Friedrich, K. (2002). Effect of particle surface treatment on the tribological performance of epoxy based nanocomposites. Wear, 253(9-10), 1086-1093. http://dx.doi.org/10.1016/S0043-1648(02)00252-1.

8. Neitzel, I., Mochalin, V., Bares, J. A., Carpick, R. W., Erdemir, A., \& Gogotsi, Y. (2012). Tribological properties of nanodiamondepoxy composites. Tribology Letters, 47(2), 195-202. http:// dx.doi.org/10.1007/s11249-012-9978-8.

9. Neitzel, I., Mochalin, V., Knoke, I., Palmese, G. R., \& Gogotsi, Y. (2011). Mechanical properties of epoxy composites with high contents of nanodiamond. Composites Science and Technology, 71(5), 710-716. http://dx.doi.org/10.1016/j. compscitech.2011.01.016.

10. Veena, M. G., Renukappa, N. M., Suresha, B., \& Shivakumar, K. N. (2011). Tribological and electrical properties of silicafilled epoxy nanocomposites. Polymer Composites, 32(12), 2038-2050. http://dx.doi.org/10.1002/pc.21221.

11. Kang, Y., Chen, X., Song, S., Yu, L., \& Zhang, P. (2012). Friction and wear behavior of nanosilica-filled epoxy resin composite coatings. Applied Surface Science, 258(17), 63846390. http://dx.doi.org/10.1016/j.apsusc.2012.03.046.

12. Xing, X. S., \& Li, R. K. Y. (2004). Wear behavior of epoxy matrix composites filled with uniform sized sub-micron spherical silica particles. Wear, 256(1-2), 21-26. http://dx.doi. org/10.1016/S0043-1648(03)00220-5.

13. Amaral, C. R., Rodriguez, R. J. S., Bessa, M. L. T., Cândido, V. S., \& Monteiro, S. N. (2014). Mechanical properties of DGEBA/TEPA modified epoxy resin. Materials Science Forum, 775-776, 588-592. http://dx.doi.org/10.4028/www. scientific.net/MSF.775-776.588.

14. Stachowiak, G. W., Batchelor, A. W., \& Stachowiak, G. B. (2004). Experimental methods in tribology. Netherlands: Elsevier.

15. Gadelmawla, E. S., Koura, M. M., Maksoud, T. M. A., Elewa, I. M., \& Soliman, H. H. (2002). Roughness parameters. Journal of Materials Processing Technology, 123(1), 133-145. http:// dx.doi.org/10.1016/S0924-0136(02)00060-2.

16. Kováŕík, T., Bělský, P., Rieger, D., Ilavsky, J., Jandová, V., Maas, M., Sutta, P., Pola, M., \& Medlín, R. (2020). Particle size analysis and characterization of nanodiamond dispersions in water and dimethylformamide by various scattering and diffraction methods. Journal of Nanoparticle Research, 22(2), 34. http://dx.doi.org/10.1007/s11051-020-4755-3.

17. Moosa, A. A., Kubba, F., Raad, M., \& Abadi, A. R. S. (2016). Mechanical and thermal properties of graphene nanoplates and functionalized carbon-nanotubes hybrid nanocomposites. American Journal of Materials Science, 6(5), 125-134. http:// dx.doi.org/10.5923/j.materials.20160605.02.

18. Moosa, A. A., Abadi, A. R. S., Kubba, F. A. K., \& Raad, M. (2017). Synergetic effects of graphene and nonfunctionalized carbon nanotubes hybrid reinforced epoxy matrix on mechanical, thermal and wettability properties of nanocomposites. American Journal of Materials Science, 7(1), 1-11. http:// dx.doi.org/10.5923/j.materials.20170701.01.

19. Rong, M. Z., Zhang, M. Q., Liu, H., Zeng, H., Wetzel, B., \& Friedrich, K. (2001). Microstructure and tribological behavior of polymeric nanocomposites. Industrial Lubrication and Tribology, 53(2), 72-77. http://dx.doi.org/10.1108/00368790110383993.

20. Amaral, C. R., Rodríguez, R. J. S., Barros Junior, L. P., Skury, A. L. D., \& Monteiro, S. N. (2012). Mechanical properties and abrasive behavior of diamond incorporated epoxy composites. Materials Science Forum, 727-728, 1757-1762. http://dx.doi. org/10.4028/www.scientific.net/MSF.727-728.1757.

21. Zhu, Z.-K., Yang, Y., Yin, J., \& Qi, Z.-N. (1999). Preparation and properties of organosoluble polyimide/silica hybrid materials by sol-gel process. Journal of Applied Polymer Science, 73(14), 2977-2984. http://dx.doi.org/10.1002/(SICI)10974628(19990929)73:14<2977::AID-APP22>3.0.CO;2-J.

22. Wetzel, B., Haupert, F., \& Zhang, M. Q. (2003). Epoxy nanocomposites with high mechanical and tribological performance. Composites Science and Technology, 63(14), 2055-2067. http://dx.doi.org/10.1016/S0266-3538(03)00115-5.

23. Saba, N., Tahir, P. M., Abdan, K., \& Ibrahim, N. A. (2016). Fabrication of epoxy nanocomposites from oil palm nano filler: mechanical and morphological properties. BioResources, 11(3), 7721-7736. http://dx.doi.org/10.15376/biores.11.3.7721-7736.

24. Saba, N., Alothman, O. Y., Almutairi, Z., Jawaid, M., \& Ghori, W. (2019). Date palm reinforced epoxy composites: tensile, impact and morphological properties. Journal of Materials Research and Technology, 8(5), 3959-3969. http://dx.doi. org/10.1016/j.jmrt.2019.07.004.

25. Zhai, Y.-J., Wang, Z.-C., Huang, W., Huang, J.-J., Wang, Y.Y., \& Zhao, Y.-Q. (2011). Improved mechanical properties of epoxy reinforced by low content nanodiamond powder. 
Materials Science and Engineering A, 528(24), 7295-7300. http://dx.doi.org/10.1016/j.msea.2011.06.053.

26. Almeida, G. R., No., Barcelos, M. V., Rodríguez, R. J. S., \& Gomez, J. G. C. (2017). Influence of encapsulated nanodiamond dispersion on $\mathrm{P}(3 \mathrm{HB})$ biocomposites properties. Materials Research, 20(3), 768-774. http://dx.doi.org/10.1590/19805373-mr-2016-0715.

27. Kubát, J., Rigdahl, M., \& Welander, M. (1990). Characterization of interfacial interactions in high density polyethylene filled with glass spheres using dynamic-mechanical analysis. Journal of Applied Polymer Science, 39(7), 1527-1539. http://dx.doi. org/10.1002/app.1990.070390711.

28. Dong, S., \& Gauvin, R. (1993). Application of dynamic mechanical analysis for the study of the interfacial region in carbon fiber/epoxy composite materials. Polymer Composites, 14(5), 414-420. http://dx.doi.org/10.1002/pc.750140508.
29. Ziegel, K. D., \& Romanov, A. (1973). Modulus reinforcement in elastomer composites. I. Inorganic fillers. Journal of Applied Polymer Science, 17(4), 1119-1131. http://dx.doi.org/10.1002/ app.1973.070170410.

30. Biswal, M., Mohanty, S., Nayak, S. K., \& Kumar, P. S. (2013). Effect of functionalized nanosilica on the mechanical, dynamicmechanical, and morphological performance of polycarbonate/ nanosilica nanocomposites. Polymer Engineering and Science, 53(6), 1287-1296. http://dx.doi.org/10.1002/pen.23388.

31. Rakha, S. A., Raza, R., \& Munir, A. (2013). Reinforcement effect of nanodiamond on properties of epoxy matrix. Polymer Composites, 34(6), 811-818. http://dx.doi.org/10.1002/pc.22480.

Received: Apr. 21, 2021

Revised: Oct. 12, 2021

Accepted: Oct. 19, 2021 